Haya: The Saudi Journal of Life Sciences

Abbreviated Key Title: Haya Saudi J Life Sci ISSN 2415-623X (Print) |ISSN 2415-6221 (Online) Scholars Middle East Publishers, Dubai, United Arab Emirates Journal homepage: https://saudijournals.com/sjls

Original Research Article

\title{
Plasma Antioxidant Levels in Bipolar Disorder
}

\author{
T Lokeshu*, V Lakshmi, V Jaya Kumari, Ch Bhargavi, P Mounika Sindhu
}

Research Scholar, Human Genetics Department, Andhra University, Visakhapatnam, Andhra Pradesh, India

DOI: $10.36348 /$ sjls.2020.v05i10.003

| Received: 06.10.2020 | Accepted: 19.10.2020 | Published: 23.10.2020

*Corresponding author: T Lokeshu

Abstract

Objective: To estimate the total antioxidant status (TAS), level of Glutathione (GSH) and Malondialdehyde (MDA) in blood plasma of bipolar disorder (BD) patients and to compare them with those in healthy controls. Materials and Methods: The levels were estimated in 154 bipolar disorder individuals and 154 age and sex matched controls without a family history of BD. All the patients included in the present study belonged to North Coastal Andhra Pradesh. Student $t$ test was used for comparison. Results: Mean blood plasma levels of TAS and GSH were significantly lower $(p=<0.05)$ while the level of MDA ( $p=0.06)$ was higher in cases compared to controls. Gender wise analysis revealed that TAS and GSH were significantly $(\mathrm{p}=0.05)$ associated with BD in both the sexes. Conclusion: A significant decrease in the level of TAS and GSH and increase of MDA in BD cases suggest the probable role of oxidative stress in the pathogenesis of BD.

Keywords: Bipolar disorder, Total antioxidant status, Glutathione, Malondialdehyde.

Copyright ( $) 2020$ The Author(s): This is an open-access article distributed under the terms of the Creative Commons Attribution 4.0 International License (CC BY-NC 4.0) which permits unrestricted use, distribution, and reproduction in any medium for non-commercial use provided the original author and source are credited.

\section{INTRODUCTION}

Bipolar disorder (BD) also known as manic depressive illness is a multifactorial disease. It is characterized by fluctuations in mood states of mania, hypomania, mixed episode and depression which may last for hours, days, weeks or months. The life time prevalence of $\mathrm{BD}$ is $1 \%$ [1-7] and the average age at onset is 21 years [40].

Antioxidants have a remarkable significance and stipulation as therapeutic agents that inhibit oxidation, besides their use in nutraceuticals, biopharmaceuticals and as food additives. Oxidation is a chemical reaction that produces free radicals which trigger cell damage by causing oxidative stress.

Free radicals are highly unstable molecules that are naturally formed when we exercise [67] and when our body converts food into energy [13]. They are also produced by activation of phagocytes, electron transport system in mitochondria, lipid peroxidation, ischemia, trauma, as a part of natural aging process [45], exposure to a variety of environmental sources such as tobacco smoke, alcohol, air pollution [38], sunlight [22] and from external resources like antineoplastic drugs [39], radiation, anesthetics, heavy metals [17], pesticides, some antibiotics and solvents
[44]. These are very reactive species with at least one unpaired electron.

\section{Oxidants}

The most important and majority of free radicals produced during normal cellular and metabolic reactions are Reactive Oxygen Species (ROS), which include Superoxide radical $(\mathrm{O} 2 *)$, Peroxyl radical (ROO*), Hydroxyl radical $\left(\mathrm{OH}^{*}\right)$, Nitric oxide (NO*), and derivatives like Hydrogen peroxide $\left(\mathrm{H}_{2} \mathrm{O}_{2}\right)$ and Hypochloran acid ( $\mathrm{HOCl})$.

In the cell, they are constantly generated in small amounts as a normal side effect of aerobic metabolism [2]. Excess amounts of ROS can be generated due to environmental determinants like UV radiation, microbes, allergens, cigarette smoke, physical determinants like intense exercise, intake of diet which is excessive in fat and carbohydrates and deficient in antioxidants. Other conditions include use of certain drugs, alcohol metabolism, and therapeutic radiation [11].

At moderate levels, they involve in immune function, cell signaling pathways and in redox regulation [37]. At higher concentration ROS can damage the integrity of various bio molecules including DNA [18], proteins [62] and lipids [69] and promote 
the activation of autophagy, apoptosis and necrosis [34].

\section{Oxidative stress}

A balance between generation and elimination of ROS is essential in maintaining healthy biological systems. Depletion of antioxidants or an imbalance between oxidants and antioxidants due to accumulation of ROS results in oxidative stress [60]. During oxidative stress, cells attempt to counteract the oxidant effects and restore the redox balance by activation or silencing of genes encoding defensive enzymes [59], transcription factors and structural proteins [31].

Oxidative stress constitutes a causative or associated risk factor for a number of human diseases such as pancreatitis [14], diabetic nephropathy, chronic complications such as cardiovascular disease [21, 66], cancer [66, 68] nervous system disease and neurodegenerative diseases [66]. It has been implicated in the pathogenesis of neuropsychiatric diseases [42, 53 ] as the brain has greater vulnerability to oxidative damage. Oxidative stress can lead to membrane lipid peroxidation which can cause impairment of signal transduction, structural plasticity and cell flexibility, all of which develops neural injury $[1,63]$.

\section{Antioxidants}

Antioxidants are natural or man- made substances that help in counteracting or delaying of cell damage caused due to oxidation. Antioxidants are unstable molecules, produced in the body and also available from dietary foods. These are also called free radical scavengers. Under physiological conditions, excess ROS are eliminated by the human antioxidant defense system. The antioxidant system includes enzymatic antioxidants like superoxide dismutase (SOD), catalase (CAT), glutathione peroxidase , and non-enzymatic antioxidants like Vitamin C, Vitamin E and glutathione etc. [25,26]. Antioxidants play a key role in preventing diseases such as cancer, cardiovascular diseases, cataracts, glaucoma, muscular degeneration, Alzheimer's disease, hypertension, autoimmune disorders, and neurodegenerative diseases [70]. Antioxidants prevent the damage caused by free radicals, help in lowering the risk of infections, prevent DNA damage [16] help in proper functioning of vital organs like heart and also help in maintaining healthy skin.

Total antioxidant status (TAS) acts as the key factor for reflecting the redox balance between oxidation and anti-oxidation. Ratio of total oxidant status (TOS) to TAS indicates the level of oxidative stress [24].

TAS is used to estimate the activity of antioxidants in a medium. It gives information regarding overall antioxidant status of an individual which also includes those antioxidants that are not measured easily [23]. In laboratories, concentrations of different oxidant species in serum can be measured separately, but the measurements are labor- intensive time- consuming, costly and require complicated techniques. So the present study estimated only TAS for the study population.

\section{Glutathione}

Glutathione (GSH) is a non-enzymatic antioxidant found in plants, animals, fungi, some bacteria and archaea. It is ubiquitous and is found in all living organisms in differential concentrations [3]. It is the "master antioxidant" and the most prominent nonenzymatic antioxidant in the human body. It is a tripeptide composed of glutamate, cysteine and glycine. Diminished GSH levels elevate cellular vulnerability towards oxidative stress, characterized by accumulating ROS. Plasma GSH appears to be a suitable biomarker for detecting underlying oxidative stress [56].

GSH protects the lipid membrane, prevents mitochondrial damage, protects against glutamate induced excitotoxicity and calcium mediated cell death by supporting the regulation of intracellular calcium levels $[35,50]$ which are elevated in both schizophrenia and $\mathrm{BD}[8,9,52]$.

GSH plays a vital role in redox signaling, xenobiotic detoxification, regulation of cell proliferation, apoptosis, immune function, detoxifying or neutralizing toxins, regeneration of antioxidants, transporting proteins inside and in between cells and fibrogenesis.

GSH serves as a biomarker in Parkinson's disease [48], the progression and pathophysiology of which is contributed by oxidative stress. Reduced plasma glutathione levels act as risk factor for cardiovascular disease, especially for cerebral small vessel disease [61]. GSH deficiency is thought to disable the cell's ability to metabolize cellular waste and impair defence against ROS and $\mathrm{H} 2 \mathrm{O} 2$. Reduction of plasma glutathione is associated with schizophrenia and BD [49].

\section{Malondialdehyde}

Malondialdehyde (MDA) is one of the end products of polyunsaturated fatty acids peroxidation and arachidonic acid metabolism in the cells. Free radicals initiate the lipid peroxidation activity in an organism. An increase in free radicals causes inflation of MDA. It is commonly known as a marker of oxidative stress or for lipid peroxidation [29]. It is found in heated edible oils such as sunflower and palm oils [19].

Lipid peroxidation is a free-radical mediated chain of reactions that results in an oxidative degeneration of polyunsaturated lipids in the biological membranes [57]. Since lipid peroxides are unstable 
compounds, they tend to degrade rapidly into a variety of secondary products like MDA. Therefore, it can be used as a marker of cell membrane injury. MDA is very unstable and readily combines with several functional groups on molecules including proteins, amino acids, lipoproteins and nucleic acid bases of DNA at physiological $\mathrm{pH}$ and forms adducts. It also involves in rapid enzymatic degradation [41].

MDA is reactive and potentially mutagenic. It exhibits mutagenic and genotoxic properties, which can lead to cancer formation. It can also be used as one of the markers for diagnosis of many health problems such as Alzheimer's disease, chronic obstructive pulmonary disease, asthma, diabetes or cardiovascular diseases, psychiatric disorders, etc. Corneas of patients suffering from keratoconus and bullous keratopathy have increased levels of MDA [12]. MDA can be found in tissue sections of joints from patients with osteoarthritis [64]. High levels of MDA was observed in serum of patients with schizophrenia and BD [42].

\section{MATERIALS AND METHODS}

The study group includes 154 bipolar manic patients attending Government Hospital for Mental Care, Visakhapatnam during October, 2015 to July, 2017. The cases were diagnosed according to ICD 10 criteria. Control group includes 154 drugs free, healthy, age and sex matched unrelated individuals without any family history of psychological disorders. The Institutional ethical committee approved the present study.

Fasting blood samples were collected after taking prior informed consent. $2 \mathrm{ml}$ of blood was drawn into anticoagulant tube. Plasma was separated by centrifuging the collected blood at $3000 \mathrm{rpm}$ for 10 minutes. Collected plasma was kept in deep freezer at $20^{\circ} \mathrm{C}$ until further analysis. Separated plasma was used for analysis of biochemical parameters like TAS, GSH using modified Owens method as described by Beutler et al. [10] and The lipid peroxidation product, MDA level was measured using the thiobarbituric acid reactive substances (TBARS) method of Satoh [58]. Student $\mathrm{t}$ test was used for comparison as the variables are continuous.

\section{RESULTS}

Mean blood plasma levels of two biochemical parameters, TAS and GSH were significantly lower among the BD patients compared to controls. Another biochemical parameter, MDA did not show significant association with $\mathrm{BD}$, despite its higher mean level in cases than in controls (Table 1).

Table-1: Plasma concentrations of TAS, GSH and MDA in BD cases and controls.

\begin{tabular}{|l|l|l|l|}
\hline $\begin{array}{l}\text { Parameter } \\
(\boldsymbol{\mu m o l} / \mathbf{L})\end{array}$ & $\begin{array}{l}\text { Cases } \\
\mathbf{N}=\mathbf{1 5 2}\end{array}$ & $\begin{array}{l}\text { Mean } \mathbf{\text { SD }} \\
\text { Controls } \\
\mathbf{N = 1 5 2}\end{array}$ & P value \\
\hline TAS & $0.9942 \pm 0.10$ & $1.1796 \pm 0.15$ & 0.0000 \\
\hline GSH & $3.7112 \pm 0.97$ & $6.3724 \pm 1.57$ & $<0.0000$ \\
\hline MDA & $5.9634 \pm 0.70$ & $3.6853 \pm 0.60$ & 0.0622 \\
\hline
\end{tabular}

\section{Genderwise analysis}

The present study includes 107 males and 45 females. Both male and female BD cases showed decreased concentration of blood plasma levels of the two biochemical parameters, TAS and GSH compared to controls (Table 2) and the difference was found to be significant. In contrast to the above biochemical parameters, MDA level in blood plasma did not show significant association in either males or females.

Table-2: Plasma concentrations of TAS, GSH and MDA in males and females of BD cases and controls

\begin{tabular}{|l|l|l|l|l|}
\hline Parameter & Gender & Mean \pm SD & P value \\
\hline & & Cases & Controls & \\
\hline TAS & Male $(\mathrm{N}=107)$ & $0.9940 \pm 0.10$ & $1.1778 \pm 0.15$ & 0.0001 \\
& Female $(\mathrm{N}=45)$ & $0.9906 \pm 0.10$ & $1.1791 \pm 0.15$ & 0.0084 \\
& & & & \\
\hline GSH & Male $(\mathrm{N}=107)$ & $3.702 \pm 0.96$ & $6.3636 \pm 1.54$ & 0.0000 \\
\hline & Female $(\mathrm{N}=45)$ & $3.7051 \pm 0.97$ & $6.4112 \pm 1.56$ & 0.0017 \\
\hline MDA & Male $(\mathrm{N}=107)$ & $5.9710 \pm 0.70$ & $3.6883 \pm 0.60$ & 0.104 \\
\hline & Female $(\mathrm{N}=45)$ & $5.9792 \pm 0.69$ & $3.6827 \pm 0.61$ & 0.4163 \\
\hline
\end{tabular}

\section{DISCUSSION}

TAS

The measurement of TAS reflects the antioxidative status of plasma [23]. TAS level in bipolar patients was evaluated in very few studies. Cingi Yirun et al. [15] reported serum TAS level in manic BD patients with lack of significant association with the disorder. Kalelioglu et al. [36] reported decreased level of TAS in serum of manic BD patients compared to controls. The present study is the first in reporting plasma TAS level in manic BD patients in India which 
is found to be significantly $(\mathrm{p}=0.000)$ associated with the disorder.

\section{GSH}

Few studies reported association between GSH and $\mathrm{BD}[20,49,54,56,65]$. All the authors reported decreased concentration of GSH in BD patients compared to controls except Tuncel et al. [65].

The present study reports decreased level of GSH in BD cases compared to controls with significant association $(\mathrm{p}=<0.0000001)$. This is in accordance with the previous studies which also reported decreased concentration of GSH in BD patients.

Nucifora et al. [49] reported that decreased level of GSH may be associated with psychosis associated pathophysiology of BD. The present study lines up with Nucifora et al. [49] report as in the present study the most common comorbid condition was psychosis and reduced level of GSH was also observed in the study population.

\section{MDA}

In clinical studies, the most widely used indicator for oxidative stress is estimation of the end product of lipid peroxidation, MDA [4, 32] through TBARS. Increased levels of lipid peroxidation product was reported in several studies in BD patients $[4,5,6,20,28,42,43,46,51,55]$. The present study reports increased concentration of MDA in BD patients compared to controls.

Frey et al. [28] and Machado et al. [46] reported increased level of TBARS in manic BD patients. Anderezza et al. [5] in their meta-analysis reported the same in all phases of BD patients. Kunz et al. [43] also reported increased level of TBARS in all phases of BD with significantly $(\mathrm{p}=0.009503)$ higher concentration in manic patients. Banarjee et al. [6] reported that increased level of TBARS in serum of BD patients was due to a shift in redox balance leading to an increased oxidative stress in BD patients.

All the above cited studies reported an increase in the concentration of MDA in BD cases compared to the controls, but significant association was observed only In Indian population [6]. The present study also shows border line significance by having a $\mathrm{p}$ value of 0.05911

\section{CONCLUSION}

BD patients exhibited significantly lower TAS and the antioxidant GSH and higher mean level of lipid peroxidation product MDA than the controls indicating the possible role of oxidative stress in the pathogenesis of BD.

\section{REFERENCES}

1. Akarsu, S., Bolu, A., Aydemir, E., Zincir, S. B., Kurt, Y. G., Zincir, S., \& Uzun, Ö. (2018). The relationship between the number of manic episodes and oxidative stress indicators in bipolar disorder. Psychiatry investigation, 15(5), 514.

2. Phaniendra, A., Jestadi, D. B., \& Periyasamy, L. (2015). Free radicals: properties, sources, targets, and their implication in various diseases. Indian journal of clinical biochemistry, 30(1), 11-26.

3. Anderson, M. E. (1998). Glutathione, an overview of biosynthesis and modulation. ChemicoBiological Interactions, 111-112, 1-14.

4. Andreazza, A. C., Kauer-Sant'Anna, M., Frey, B. N., Bond, D. J., Kapczinski, F., Young, L. T., \& Yatham, L. N. (2008). Oxidative stress markers in bipolar disorder: a meta-analysis. Journal of affective disorders, 111(2-3), 135-144.

5. Andreazza, A. C., Cassini, C., Rosa, A. R., Leite, M. C., de Almeida, L. M., Cunha, A. B., ... \& Kapczinski, F. (2007). Serum S100B and antioxidant enzymes in bipolar patients. Journal of psychiatric research, 41(6), 523-529.

6. Banerjee, U., Dasgupta, A., Rout, J., \& Singh, O. (2012). Effects of lithium therapy on $\mathrm{Na}+\mathrm{K}+-$ ATPase activity and lipid peroxidation in bipolar disorder. Prog Neuropsychopharmacol Biol Psychiatry, 37, 56-61.

7. Bebbington, P., \& Ramana, R. (1995). The epidemiology of bipolar affective disorder. Soc Psychiatry Psychiatr Epidemiol, 30(6), 279-292.

8. Berk, M., Plein, H., Belsham. (2000). B. Life Sci., 66, 2427-2432.

9. Berk, M., Plein, H., Csizmadia, T. (1999). Int. Clin. Psychopharmacol, 14, 119-122.

10. Beutler, E., Duvon, 0., \& Kelly, M. B. (1963). J. Lab. clin. Med. 61, 882.

11. Bouayed, J., \& Bohn, T. (2010). Exogenous antioxidants - double-edged swords in cellular redox state: health beneficial effects at physiologic doses versus deleterious effects at high doses. Oxidative medicine and cellular longevity, 3(4), 228-237.

12. Buddi, R., Lin, B., Atilano, S. R., Zorapapel, N. C., Kenney, M. C., \& Brown, D. J. (2002). Evidence of oxidative stress in human corneal diseases. Journal of Histochemistry \& Cytochemistry, 50(3), 341-351.

13. Cadenas, E., \& Davies, K. J. (2000). Mitochondrial free radical generation, oxidative stress, and aging. Free radical biology and medicine, 29(3-4), 222-230

14. Winterbourn, C. C., Bonham, M. J., Buss, H., AbuZidan, F. M., \& Windsor, J. A. (2003). Elevated protein carbonyls as plasma markers of oxidative stress in acute pancreatitis. Pancreatology, 3(5), 375-382.

15. Cingi Yirün, M., Ünal, K., Altunsoy Şen, N., Yirün, O., Aydemir, Ç., \& Göka, E. (2016). Evaluation of Oxidative Stress in Bipolar Disorder 
in terms of Total Oxidant Status, Total Antioxidant Status, and Oxidative Stress Index. Noro psikiyatri arsivi, 53(3), 194-198.

16. Collins. (1999). Collins AR. Oxidative DNA damage, antioxidants, and cancer. Bioessays Mar, 21(3), 238-46.

17. De Vos, C. H. R., \& Schat, H. (1991). Free radicals and heavy metal tolerance. In J. Rozema \& J. A. C. Verkleij (Eds.), Ecological responses to environmental stress (pp. 22-31). Dordrecht: Springer Netherlands.

18. Dizdaroglu, M., Jaruga, P., Birincioglu, M., \& Rodriguez, H. (2002). Free radical-induced damage to DNA: mechanisms and measurement. Free Radical Biology and Medicine, 32(11), 1102-1115.

19. Doureradjou, P., \& Koner, B. C. (2008). Effect of different cooking vessels on heat induced lipid peroxidation of different edible oils. Journal of food biochemistry, 32(6), 740-751.

20. Dubey, R. K., Khan, S. A., Neupane, Y., Shyangwa, P. M., Baral, N., \& Lamsal, M. Bipolar Affective Disorder.

21. Elahi, M. M., Kong, Y. X., \& Matata, B. M. (2009). Oxidative stress as a mediator of cardiovascular disease. Oxidative medicine and cellular longevity, 2(5), 259-269.

22. Emri, G., Horkay, I., \& Remenyik, E. (2006). The role of free radicals in the UV-induced skin damage. Photo-aging. Orvosi hetilap, 147(16), 731.

23. Erel, O. (2004). A novel automated method to measure total antioxidant response against potent free radical reactions. Clin Biochem, 37(2), 112119.

24. Erel, O. (2005). A new automated colorimetric method for measuring total oxidant status. Clin Biochem, 38(12), 1103-1111.

25. Birben, E., Sahiner, U. M., Sackesen, C., Erzurum, S., \& Kalayci, O. (2012). Oxidative stress and antioxidant defense. World Allergy Organization Journal, 5(1), 9-19.

26. Matough, F. A., Budin, S. B., Hamid, Z. A., Alwahaibi, N., \& Mohamed, J. (2012). The role of oxidative stress and antioxidants in diabetic complications. Sultan Qaboos University Medical Journal, 12(1), 5.

27. Kapczinski, F., Dal-Pizzol, F., Teixeira, A. L., Magalhaes, P. V., Kauer-Sant'Anna, M., Klamt, F., \& Gama, C. S. (2011). Peripheral biomarkers and illness activity in bipolar disorder. Journal of psychiatric research, 45(2), 156-161.

28. Frey, B. N., Andreazza, A. C., Kunz, M., Gomes, F. A., Quevedo, J., Salvador, M., Kapczinski, F. (2007). Increased oxidative stress and DNA damage in bipolar disorder: a twin-case report. Prog Neuropsychopharmacol Biol Psychiatry, 31(1), 283-285.

29. Gaweł, S., Wardas, M., Niedworok, E., \& Wardas, P. (2004). [Malondialdehyde (MDA) as a lipid peroxidation marker]. Wiadomosci lekarskie (Warsaw, Poland : 1960), 57(9-10), 453-45
30. Gawryluk, J. W., Wang, J. F., Andreazza, A. C., Shao, L., \& Young, L. T. (2011). Decreased levels of glutathione, the major brain antioxidant, in postmortem prefrontal cortex from patients with psychiatric disorders. International Journal of Neuropsychopharmacology, 14(1), 123-130.

31. Ghosh, R., \& Mitchell, D. L. (1999). Effect of oxidative DNA damage in promoter elements on transcription factor binding. Nucleic acids research, 27(15), 3213-3218.

32. Grignon, S., \& Chianetta, J. M. (2007). Assessment of malondialdehyde levels in schizophrenia: a meta-analysis and some methodological considerations. Progress in NeuroPsychopharmacology and Biological Psychiatry, 31(2), 365-369.

33. Halliwell, B. (2001). Free Radicals and other reactive species in disease. Nature Encyclopedia of life sciences, 1-7.

34. He, L., He, T., Farrar, S., Ji, L., Liu, T., \& Ma, X. (2017). Antioxidants maintain cellular redox homeostasis by elimination of reactive oxygen species. Cellular Physiology and Biochemistry, 44(2), 532-553.

35. Jain, A., Mårtensson, J., Stole, E., Auld, P. A., \& Meister, A. (1991). Glutathione deficiency leads to mitochondrial damage in brain. Proceedings of the National Academy of Sciences of the United States of America, 88(5), 1913-1917.

36. Kalelioglu, T., Genc, A., Karamustafalioglu, N., Tasdemir, A., Can Gungor, F., Cansiz, A., . . . Emul, M. (2014). Initial and post-treatment total oxidant-antioxidant status and oxidative stress index in male patients with manic episode. Psychiatry Res, 218(1-2), 249-251.

37. Kamata, H., \& Hirata, H. (1999). Redox regulation of cellular signalling. Cellular signalling, 11(1), 114.

38. Kelly, F. J. (2003). Oxidative stress: its role in air pollution and adverse health effects. Occupational and environmental medicine, 60(8), 612-616.

39. Kenneth, A. Conklin. (2004). Free Radicals, the Pros and Cons of Antioxidants. Cancer Chemotherapy and Antioxidants. Jonsson Comprehensive Cancer Center, UCLA, Los Angeles, CA 90095-1778.

40. Kessler, R. C., Rubinow, D. R., Holmes, C., Abelson, J. M., \& Zhao, S. (1997). The epidemiology of DSM-III-R bipolar I disorder in a general population survey. Psychol Med, 27(5), 1079-1089.

41. Khoubnasabjafari, M., Ansarin, K., \& Jouyban, A. (2015). Reliability of malondialdehyde as a biomarker of oxidative stress in psychological disorders. BioImpacts: BI, 5(3), 123.

42. Kuloglu, M., Ustundag, B., Atmaca, M., Canatan, H., Tezcan, A. E., \& Cinkilinc, N. (2002). Lipid peroxidation and antioxidant enzyme levels in patients with schizophrenia and bipolar 
disorder. Cell biochemistry and function, 20(2), 171-175.

43. Kunz, M., Gama, C., Andreazza, A., Salvador, M., Ceresér, K., Gomes, F., Kapczinski, F. (2008). Elevated serum superoxide dismutase and thiobarbituric acid reactive substances in different phases of bipolar disorder and in schizophrenia. Prog Neuropsychopharmacol Biol Psychiatry, 32, 1677-1681.

44. Lamy-Freund, M.T., Ferreira, V.F., Schreier, S. (1985). Mechanism of inactivation of the polyene antibiotic amphotericin B. Evidence for radical formation in the process of autooxidation. $\mathrm{J}$ Antibiot (Tokyo). Jun, 38(6), 753-7.

45. Lobo, V., Patil, A., Phatak, A., \& Chandra, N. (2010). Free radicals, antioxidants and functional foods: Impact on human health. Pharmacognosy reviews, 4(8), 118.

46. Machado-Vieira, R., Andreazza, A. C., Viale, C. I., Zanatto, V., Cereser, V., Jr., da Silva Vargas, R.,Gentil, V. (2007). Oxidative stress parameters in unmedicated and treated bipolar subjects during initial manic episode: a possible role for lithium antioxidant effects. Neurosci Lett, 421(1), 33-36.

47. Machado-Vieira, R., Manji, H.K., Zarate, C.A., (2009). The role of the tripartite glutamatergic synapse in the pathophysiology and therapeutics of mood disorders. Neuroscientist 15, 525-539.

48. Mischley, L. K., Standish, L. J., Weiss, N. S., Padowski, J. M., Kavanagh, T. J., White, C. C., \& Rosenfeld, M. E. (2016). Glutathione as a biomarker in Parkinson's disease: Associations with aging and disease severity. Oxidative medicine and cellular longevity, 2016.

49. Nucifora, L., Tanaka, T., Hayes, L., Kim, M., Lee, B., Matsuda, T., Sawa, A. (2017). Reduction of plasma glutathione in psychosis associated with schizophrenia and bipolar disorder in translational psychiatry. Translational Psychiatry, 7, e1215

50. Oja, S. S., Janáky, R., Varga, V., \& Saransaari, P. (2000). Modulation of glutamate receptor functions by glutathione. Neurochemistry international, 37(23), 299-306.

51. Ozcan, M. E., Gulec, M., Ozerol, E., Polat, R., \& Akyol, O. (2004). Antioxidant enzyme activities and oxidative stress in affective disorders. International clinical psychopharmacology, 19(2), 89-95.

52. Plein, H., \& Berk, M. (2001). The platelet as a peripheral marker in psychiatric illness. Human Psychopharmacology: Clinical and Experimental, 16(3), 229-236.

53. Ranjekar, P. K., Hinge, A., Hegde, M. V., Ghate, M., Kale, A., Sitasawad, S., \& Mahadik, S. P. (2003). Decreased antioxidant enzymes and membrane essential polyunsaturated fatty acids in schizophrenic and bipolar mood disorder patients. Psychiatry research, 121(2), 109-122.

54. Raffa, M., Barhoumi, S., Atig, F., Fendri, C., Kerkeni, A., \& Mechri, A. (2012). Reduced antioxidant defense systems in schizophrenia and bipolar I disorder. Prog Neuropsychopharmacol Biol Psychiatry, 39(2), 371-375.

55. Ranjekar, P. K., Hinge, A., Hegde, M. V., Ghate, M., Kale, A., Sitasawad, S., ... \& Mahadik, S. P. (2003). Decreased antioxidant enzymes and membrane essential polyunsaturated fatty acids in schizophrenic and bipolar mood disorder patients. Psychiatry research, 121(2), 109-122.

56. Rosa, A. R., Singh, N., Whitaker, E., de Brito, M., Lewis, A. M., Vieta, E., Goodwin, G. M. (2014). Altered plasma glutathione levels in bipolar disorder indicates higher oxidative stress; a possible risk factor for illness onset despite normal brain-derived neurotrophic factor (BDNF) levels. Psychol Med, 44(11), 2409-2418.

57. Rosenblum, E. R., Gavaler, J. S., Van Thiel, D. H. (1989). Lipid peroxidation: a mechanism for alcohol-induced testicular injury.Free Radical Biology and Medicine, 7(5), 569-577.

58. Satoh, K. (1978). Serum lipid peroxide in cerebrovascular disorders determined by a new colorimetric method. Clin Chim Acta. 90. 37-43.

59. Scandalios, J. G. (2006). Genomic responses to oxidative stress. Reviews in Cell Biology and Molecular Medicine.

60. Scandalios, J. G. (1997). Oxidative stress and the molecular biology of antioxidant defenses (No. 04; QP177, S2.).

61. Shimizu, H., Kiyohara, Y., Kato, I., Kitazono, T., Tanizaki, Y., Kubo, M., \& Iida, M. (2004). Relationship between plasma glutathione levels and cardiovascular disease in a defined population: the Hisayama study. Stroke, 35(9), 2072-2077.

62. Stadtman, E. R., \& Levine, R. L. (2000). Protein oxidation. Annals of the New York Academy of Sciences, 899(1), 191-208.

63. Takuma, K., Baba, A., \& Matsuda, T. (2004). Astrocyte apoptosis: implications for neuroprotection. Progress in neurobiology, 72(2), 111-127.

64. Tiku, M. L., Narla, H., Jain, M., \& Yalamanchili, P. (2007). Glucosamine prevents in vitro collagen degradation in chondrocytes by inhibiting advanced lipoxidation reactions and protein oxidation. Arthritis Research \& Therapy, 9(4), R76.

65. Tuncel, O. K., Sarisoy, G., Bilgici, B., Pazvantoglu, O., Cetin, E., Unverdi, E., Boke, O. (2015). Oxidative stress in bipolar and schizophrenia patients. Psychiatry Res, 228(3), 688-694.

66. Valko, M., Leibfritz, D., Moncol, J., Cronin, M. T., Mazur, M., \& Telser, J. (2007). Free radicals and antioxidants in normal physiological functions and human disease. The international journal of biochemistry \& cell biology, 39(1), 44-84.

67. VinÑa, J., Gomez- Cabrera, M. C., Lloret, A., Marquez, R., Minana, J. B., Pallardó, F. V., \& Sastre, J. (2000). Free radicals in exhaustive 
physical exercise: mechanism of production, and protection by antioxidants. IUBMB life, 50(4- 5), 271-277.

68. Wu, D., \& Cederbaum, A. I. (2003). Alcohol, oxidative stress, and free radical damage. Alcohol research \& health: the journal of the National
Institute on Alcohol Abuse and Alcoholism, 27(4), 277-284.

69. Yla-Herttuala, S. (1999). Oxidized LDL and atherogenesis. Ann N Y Acad Sci, 874,134-7.

70. Young, I. S., \& Woodside, J. V. (2001). Antioxidants in health and disease. Journal of clinical pathology, 54(3), 176-186. 